\title{
6-Nitro-1,4-di(prop-2-yn-1-yl)quinoxaline-2,3(1H,4H)-dione (NQPr) - a novel corrosion inhibitor for mild steel in hydrochloric acid environment
}

\author{
A. El Janati, ${ }^{1}$ Y. Kandri Rodi, ${ }^{1}$ M. Mokhtari, ${ }^{2}$ I.Abdel-Rahman, ${ }^{3}$ \\ I. Alaoui, ${ }^{1}$ F. Ouazzani Chahdi, ${ }^{1}$ Y. Ouzidan, ${ }^{1}$ H. Steli, ${ }^{4}$ H. Elmsellem ${ }^{5 *}$ \\ and B. Hammouti ${ }^{5}$
}

${ }^{1}$ Laboratory of Applied Organic Chemistry, Faculty of Science and Technology, University Sidi Mohammed Ben Abdallah, Fez, Morocco

${ }^{2}$ University of Echahid Hamma Lakhdar, PO Box 789, El-Oued, Algeria

${ }^{3}$ Department of Chemistry, College of Sciences, University of Sharjah, PO Box: 27272, UAE

${ }^{4}$ Mechanical \& Energy Laboratory, Faculty of Sciences, Mohammed Premier University,

Oujda, Morocco

${ }^{5}$ Laboratoire de chimieanalytique appliquée, matériaux et environnement (LC2AME),

Facultédes Sciences, B.P. 717, 60000 Oujda, Morocco

*E-mail: h.elmsellem@gmail.com

\begin{abstract}
The novel synthesis of 6-nitro-1,4-di(prop-2-yn-1-yl)quinoxaline-2,3(1H,4H)-dione, and its corrosion inhibition effect on mild steel in $1.0 \mathrm{M} \mathrm{HCl}$ solution was evaluated through electrochemical impedance spectroscopy (EIS), potentiodynamic polarization (Tafel), gravimetric and density functional theory (DFT) methods. The changes of corrosion current density and impedance modulus of mild steel in different concentrations of corrosion inhibitor solutions showed that the 6-nitro-1,4-di(prop-2-yn-1-yl)quinoxaline-2,3(1H,4H)-dione presented a valid protective effect on mild steel in $1.0 \mathrm{M} \mathrm{HCl}$ environment. The inhibition efficiency of 6-nitro-1,4-di(prop-2-yn-1-yl)quinoxaline-2,3(1H,4H)-dione on mild steel increases by increasing its concentration. Results showed that 6-chloro-1,4-di(prop-2-yn-1yl)quinoxaline-2,3(1H,4H)-dione acted as mixed type inhibitor. The 6-nitro-1,4-di(prop-2-yn1-yl)quinoxaline-2,3(1H,4H)-dione exhibited the maximum inhibition efficiency of about $93 \%$ at a concentration of $1.0 \times 10^{-3} \mathrm{M}$. Adsorption of 6-nitro-1,4-di(prop-2-yn-1-yl)quinoxaline2,3(1H,4H)-dione obeyed the Langmuir adsorption isotherm model. Gibbs free energy of adsorption $\left(\Delta G_{\text {ads }}\right)$, adsorption constant $\left(K_{\text {ads }}\right)$ and activation energy $\left(E_{\mathrm{a}}\right)$ values showed that the inhibitor 6-nitro-1,4-di(prop-2-yn-1-yl)quinoxaline-2,3(1H,4H)-dione is strongly and spontaneously adsorbed on the mild steel surface/electrolyte interface. The inhibitive properties of 6-nitro-1,4-di(prop-2-yn-1-yl)quinoxaline-2,3(1H,4H)-dione obtained from experimental method was supported by DFT. Numerous parameters were computed and discussed in order to describe its adsorption behavior.
\end{abstract}

Key words: inhibitor, corrosion protection, mild steel, $\mathrm{HCl}$ solution, DFT.

Received: July 2, 2019. Published: September 3, 2019

doi: 10.17675/2305-6894-2019-8-3-17 


\section{Introduction}

In recent years, quinoxalines have been of great interest to chemists and biologists because of their innumerable pharmaceutical and therapeutic properties $[1,2]$. Indeed, quinoxaline is among the oldest heterocyclic systems whose synthetic chemistry has been evolving for centuries, and its exploitation varied from agro-chemistry and biology, to medicine and therapy [3-5] and to the existence of insecticides [6].

In the previous study, theoretical and experimental studies on the corrosion inhibition potential of 6-chloro-1,4-di(prop-2-yn-1-yl)quinoxaline-2,3(1H,4H)-dione has been carried [7]. In this work, the study is extended to synthesize and study the corrosion efficiency of 6-nitro analogue (NQPr) (Scheme 1).
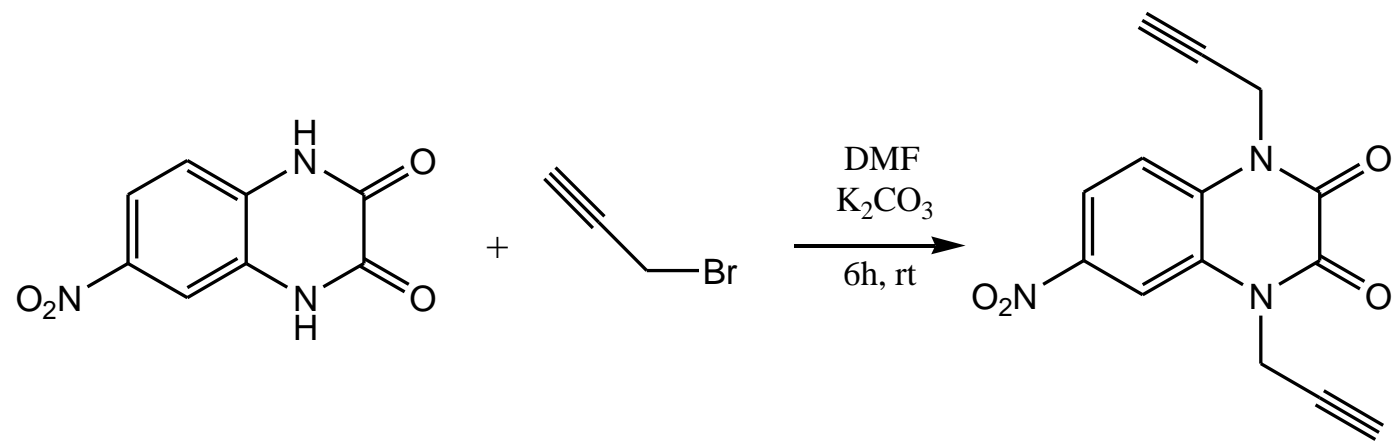

\section{Preparation of corrosive medium}

The concentration of the corrosive solution that was used in this work was $1.0 \mathrm{M} \mathrm{HCl}$. This solution was prepared from the concentrated $37 \% \mathrm{HCl}$ reagent by dilution with distilled water. The molarity of $\mathrm{HCl}$ solution was determined using a standard $\mathrm{NaOH}$ solution.

\section{II.1. Preparation of mild steel coupons and inhibitor NQPr}

Mild steel sheet was obtained commercially. The used mild steel coupons have percent composition (\% wt.) of $0.09 \% \mathrm{P}, 0.38 \% \mathrm{Si}, 0.01 \% \mathrm{Al}, 0.05 \% \mathrm{Mn}, 0.21 \% \mathrm{C}, 0.05 \% \mathrm{~S}$ and $99.21 \% \mathrm{Fe}$. The coupons were abraded using emery paper (400-1200 grit); and then rinsed with distilled water, degreased with acetone and dried with warm air before use. The concentrations of $1.0 \times 10^{-3}$ to $1.0 \times 10^{-6} \mathrm{M}$ of inhibitor NQPr in $1.0 \mathrm{M} \mathrm{HCl}$ were prepared by vigorous stirring at room temperature. The volume of the solution for each run was $100 \mathrm{ml}$ of $1.0 \mathrm{M} \mathrm{HCl}$ with inhibitor. The blank test solution was also $100 \mathrm{ml}$ of $1.0 \mathrm{M} \mathrm{HCl}$, but without inhibitor. All tests were performed in aerated medium at constant temperature of $308 \mathrm{~K}$ and under atmospheric pressure by the three methods: gravimetric, polarization and EIS.

\section{II.2. Weight loss, polarization and EIS measurements}

Weight loss measurements were carried out in a double walled glass cell equipped with a thermostat-cooling condenser at $308 \mathrm{~K}$. The dimensions of coupons were $1.5 \mathrm{~cm} \times 1.5 \mathrm{~cm} \times$ 
$0.05 \mathrm{~cm}$. They were immersed in $1.0 \mathrm{M} \mathrm{HCl}$ solution in the absence and presence of various inhibitor concentrations for 6 hours. The specimens were washed with doubledistilled water, dried and then weighed before and after each run. The corrosion rate was presented as $\mathrm{mg} \cdot \mathrm{cm}^{-2} \cdot \mathrm{h}^{-1}$.

The corrosion rate $(v)$ was calculated using the following equation:

$$
v=\frac{W}{S t}
$$

Where, $W$ is the average weight loss, $S$ is the total coupon area, and $t$ is the immersion time. The inhibition efficiency $\left(E_{\mathrm{w}}\right)$ was calculated using following equation:

$$
E_{\mathrm{W}} \%=\frac{v_{0}-v}{v_{0}} \times 100
$$

Where, $v_{0}$ and $v$ are the corrosion rate without and with inhibitor, respectively.

Electrochemical measurements were obtained in a three-electrode configuration. In this system, mild steel was the working electrode (WE) in the form of disc cut with $1.0 \mathrm{~cm}^{2}$ surface area which embedded in polytetrafluoro ethylene; a saturated calomel electrode (SCE) was the reference electrode and the disc platinum electrode was the auxiliary electrode. The electrochemical analyzer was PGZ100 potentiostat which was piloted by Volta master software. The polarization curves are obtained from -800 to $-200 \mathrm{mV}$ with a scan rate of $0.5 \mathrm{mV} \cdot \mathrm{s}^{-1}$. The electrodes reached the stable open circuit potentials after 30 minutes; therefore the exposure time was 30 minutes for each electrochemical measurement. The electrochemical impedance spectroscopy (EIS) measurements were carried out at open circuit potential values for each electrode between $100 \mathrm{kHz}$ and $10 \mathrm{MHz}$ frequency region and sine wave voltage was $10 \mathrm{mV}$ (peak to peak). All experiments were repeated three times to ensure the reproducibility of results.

The plot of the voltage $(E)$ versus natural $\log$ arithmic current $(\log i)$ in the anodic and cathodic Tafel regions gives the corresponding Tafel slopes $\left(\beta_{\mathrm{a}}\right.$ and $\left.\beta_{\mathrm{c}}\right)$. The percentage inhibition efficiency $\left(E_{\mathrm{p}} \%\right)$ values were calculated using the following equation:

$$
E_{\mathrm{p}} \%=\left(i_{\text {corr }(0)}-i_{\text {corr(inh })} / i_{\text {corr }(0)}\right) \times 100
$$

where $i_{\text {corr( }(0)}$ and $i_{\text {corr(inh) }}$ represent corrosion current density values without and with inhibitor, respectively.

\section{Synthesis section}

III.1. Preparation of 6-nitro-1,4-di(prop-2-yn-1-yl)quinoxaline-2,3(1H,4H)-dione (NQPr)

To a solution of $0.3 \mathrm{~g}(1.45 \mathrm{mmol})$ of 6-nitro-1,4-dihydroquinoxaline-2,3-dione in $20 \mathrm{ml}$ of dimethylformamide (DMF), $0.50 \mathrm{~g}(3.62 \mathrm{mmol})$ of potassium carbonate and $0.1 \mathrm{mmol}$ of tetra-n-butyl ammonium were added. After $10 \mathrm{~min}$ of stirring $0.43 \mathrm{~g}(3.62 \mathrm{mmol})$ of propargyl bromide was added, then the mixture was allowed to stir at room temperature for 
6 hours. After filtration of salts, the DMF solvent was evaporated under reduced pressure and the residue was dissolved in dichloromethane. The organic phase was dried over $\mathrm{Na}_{2} \mathrm{SO}_{4}$ and then concentrated. Finally, the product was separated from the mixture using silica gel column chromatography and a mixture of hexane/ethyl acetate with a ratio of $(3 / 1)$ by volume as an eluent.

\section{III.2. Spectral data measurements}

The spectroscopic characterization of the synthesized compound (NQPr) is achieved by recording ${ }^{1} \mathrm{H}$ and ${ }^{13} \mathrm{C}$ NMR spectra (Bruker Avance DPX300), (Figures 1 and 2). TLC and column chromatography were performed using silica plates and silica gel, respectively.

${ }^{1} \mathrm{H}$ NMR (300 MHz, DMSO) $\delta$ ppm: $3.42(\mathrm{t}, \mathrm{H},(\mathrm{C} \equiv \mathrm{CH})$ ); $3.46(\mathrm{t}, \mathrm{H},(\mathrm{C} \equiv \mathrm{CH})) ; 5.03$ $\left(\mathrm{d}, 2 \mathrm{H}, \mathrm{CH}_{2}\right) ; 5.09\left(\mathrm{~d}, 2 \mathrm{H}, \mathrm{CH}_{2}\right) ; 7.71\left(\mathrm{~d}, 1 \mathrm{H}, \mathrm{CH}_{\text {arom }}\right) ; 7.24\left(\mathrm{dd}, 1 \mathrm{H}, \mathrm{CH}_{\text {arom }}\right) ; 7.31(\mathrm{~d}, 1 \mathrm{H}$, $\left.\mathrm{CH}_{\text {arom }}\right) .{ }^{13} \mathrm{C}$ NMR $(75 \mathrm{MHz}, \mathrm{DMSO}) \delta \mathrm{ppm}: 153.49(\mathrm{C}=\mathrm{O}) ; 153.23(\mathrm{C}=\mathrm{O}) ; 143.32(\mathrm{Cq})$; $131.98(\mathrm{Cq}) ; 126.99(\mathrm{Cq}) ; 119.73\left(\mathrm{CH}_{\text {arom }}\right) ; 116.89\left(\mathrm{CH}_{\text {arom }}\right) ; 111.36\left(\mathrm{CH}_{\text {arom }}\right) ; 78.72(\mathrm{Cq})$; $78.67(\mathrm{Cq}) ; 76.70(\mathrm{C} \equiv \mathrm{CH}) ; 76.41(\mathrm{C} \equiv \mathrm{CH}) ; 33.36\left(\mathrm{~N}-\mathrm{CH}_{2}\right) ; 33.03\left(\mathrm{~N}-\mathrm{CH}_{2}\right)$.

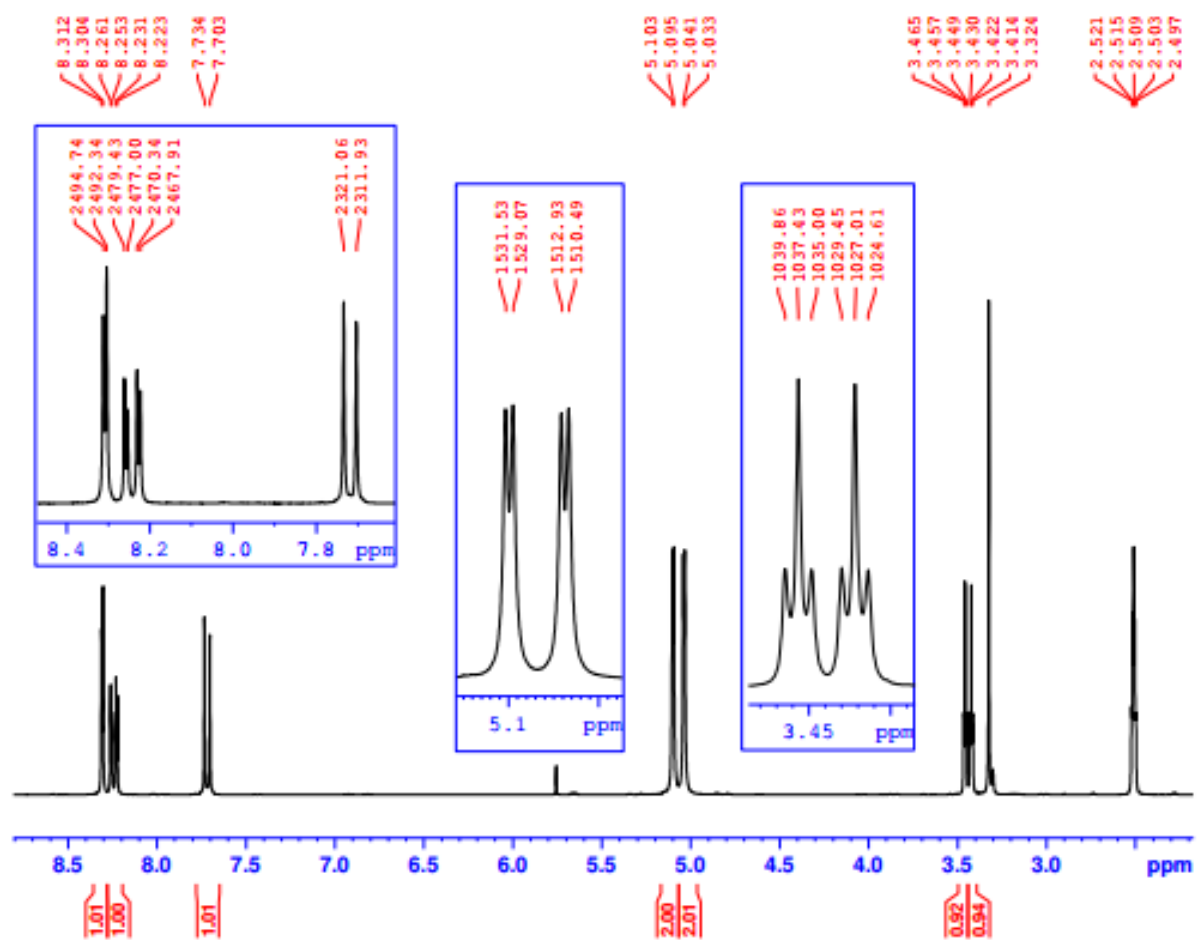

Figure 1. ${ }^{1} \mathrm{H}$ NMR spectrum of 6-nitro-1,4-di(prop-2-yn-1-yl)quinoxaline-2,3(1H,4H)-dione (NQPr). 


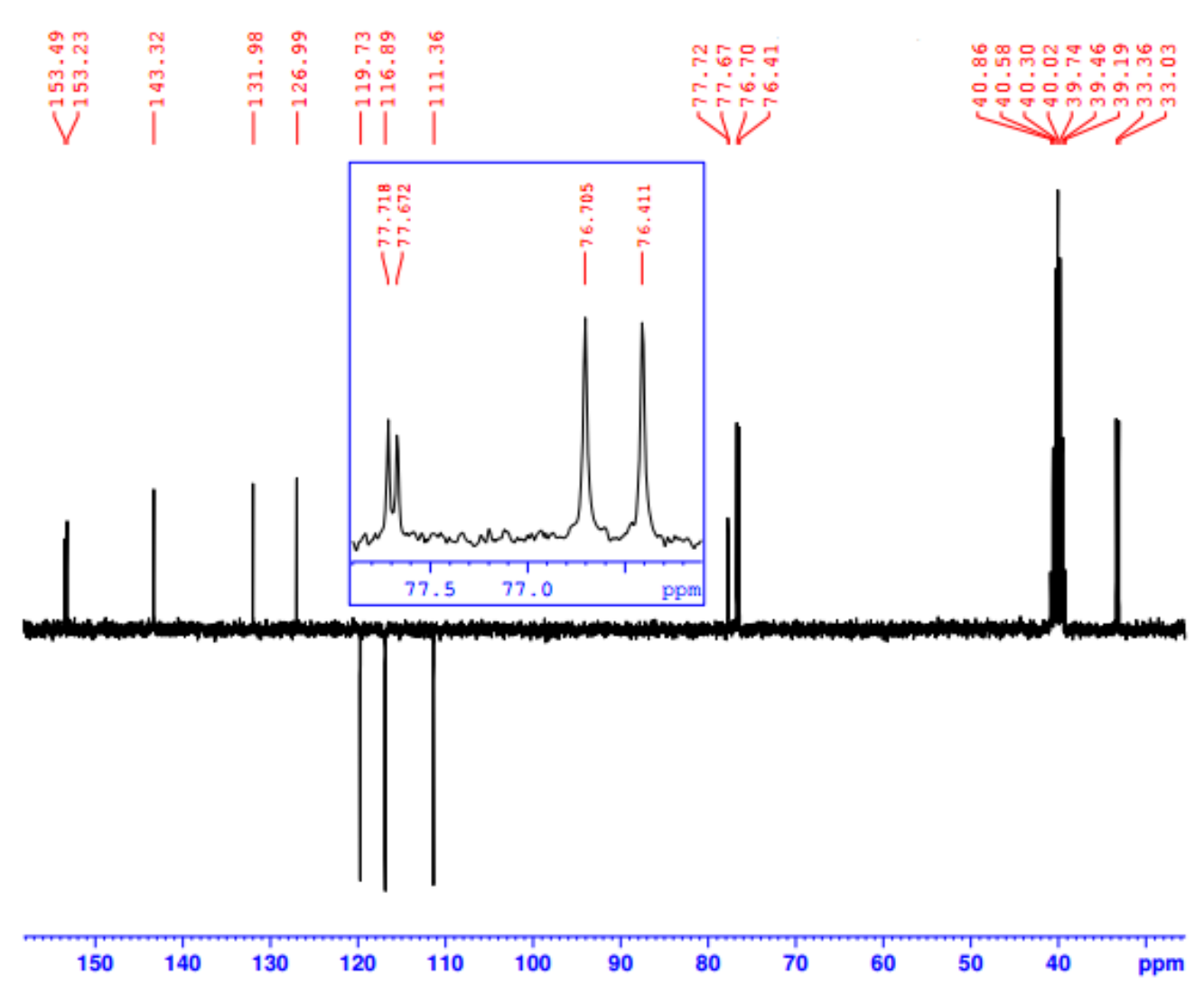

Figure 2. ${ }^{13} \mathrm{C}$ NMR spectrum of 6-nitro-1,4-di(prop-2-yn-1-yl)quinoxaline-2,3(1H,4H)-dione.

\section{Quantum Chemical Calculations}

All the quantum chemical calculations have been carried out with Gaussian 09 program package $[8,9]$. In this study, the calculations were done using B3LYP. A hybrid functional of the DFT method, which consists of the Becke's three parameters; exact exchange functional B3 combined with the non local gradient corrected correlation functional of Lee-Yang-Par (LYP) has been used along with 6-31G(d,p) basis set. In the process of geometry optimization for the fully relaxed method, convergence of all the calculations has been confirmed by the absence of imaginary frequencies. The aim of the calculations is to find the following quantum chemical indices: the energy of highest occupied molecular orbital $\left(E_{\mathrm{HOMO}}\right)$, the energy of lowest unoccupied molecular orbital $\left(E_{\mathrm{LUMO}}\right)$, energy gap $(\Delta E)$, hardness $(\eta)$, softness $(\sigma)$, electrophilicity index $(\omega)$, the fraction of electrons transferred $(\Delta N)$ from inhibitor molecule to the metal surface, and the energy change when both processes occur, namely, and correlate these values with the experimental results.

\section{IV.1. Theory and computational details}

The theoretical study of this nitro quinoxaline derivative inhibitor in hydrochloric acid as corrosion inhibitor was done using the Density Functional Theory (DFT) with the B3LYP/6-31G(d, p) method implemented in Gaussian 09 program package [10]. 
In this study, some molecular properties were calculated such as the frontier molecular orbital (HOMO and LUMO) energies, energy gap $\left(E_{\text {Gap }}\right)$, charge distribution, electron affinity $(A)$ and ionization energy.

Popular qualitative chemical concepts such as electro negativity $[11,12](\chi)$ and hardness [13] $(\eta)$ have been provided with rigorous definitions within the purview of conceptual density functional theory [14-16].

Using a finite difference method, working equations for the calculation of $\chi$ and $\eta$ can be given as [14]:

$$
\begin{gathered}
\chi=\frac{I+A}{2} \text { or } \chi=\frac{E_{\mathrm{HOMO}}+E_{\mathrm{LUMO}}}{2} \\
\eta=\frac{I-A}{2} \text { or } \eta=-\frac{E_{\mathrm{HOMO}}-E_{\mathrm{LUMO}}}{2}
\end{gathered}
$$

The fraction of transferred electrons $\Delta N$ was calculated according to Pearson theory [17]. This parameter evaluates the electronic flow in a reaction of two systems with different electro negativities, in particular case; a metallic surface $(\mathrm{Fe})$ and an inhibitor molecule. $\Delta N$ is given as follows:

$$
\Delta N=\frac{\chi_{\mathrm{Fe}}-\chi_{\mathrm{inh}}}{2\left(\eta_{\mathrm{Fe}}+\eta_{\mathrm{inh}}\right)}
$$

where $\chi_{\mathrm{Fe}}$ and $\chi_{\mathrm{inh}}$ denote the absolute electronegativity of an iron atom $(\mathrm{Fe})$ and the inhibitor molecule, respectively; $\eta_{\mathrm{Fe}}$ and $\eta_{\text {inh }}$ denote the absolute hardness of Fe atom and the inhibitor molecule, respectively. In order to apply the Eq. 6 in the present study, a theoretical value for the electronegativity of bulk iron was used $\chi_{\mathrm{Fe}}=7 \mathrm{eV}$ and a global hardness of $\eta_{\mathrm{Fe}}=0$, by assuming that for a metallic bulk $I=A$ because they are softer than the neutral metallic atoms [17].

The electrophilicity has been introduced by Sastri et al. [18], is a descriptor of reactivity that allows a quantitative classification of the global electrophilic nature of a compound within a relative scale. They have proposed the $\omega$ as a measure of energy lowering owing to maximal electron flow between donor and acceptor and $\omega$ is defined as follows.

$$
\omega=\frac{\chi^{2}}{2 \eta}
$$

The softness $\sigma$ is defined as the inverse of the $\eta[19]$.

$$
\sigma=\frac{1}{\eta}
$$




\section{Results and discussion}

\section{V.1. Weight loss measurements}

The values of the corrosion rate, inhibition efficiencies and the surface coverage of mild steel in the absence and presence of different concentrations of the inhibitor 6-nitro-1,4di(prop-2-yn-1-yl)quinoxaline-2,3(1H,4H)-dione obtained from weight loss measurements at $308 \mathrm{~K}$ are listed in Table 1 . The results in Table 1 show that the 6-nitro-1,4-di(prop-2yn-1-yl)quinoxaline-2,3(1H,4H)-dione inhibitor acts as a good corrosion inhibitor for mild steel in $1.0 \mathrm{M} \mathrm{HCl}$ solution. The results also indicate that the corrosion rate decreases as the concentration of the inhibitor increases while the inhibition efficiency increases as the inhibitor concentration increases reaching a maximum inhibition efficiency of $93 \%$ for a concentration of $1.0 \times 10^{-3} \mathrm{M}$ in $1.0 \mathrm{M} \mathrm{HCl}$ solution.

Table 1. The corrosion rate, inhibition efficiency and the surface coverage for mild steel in $1.0 \mathrm{M} \mathrm{HCl}$ solution in the absence and presence of 6-nitro-1,4-di(prop-2-yn-1-yl)quinoxaline-2,3(1H,4H)-dione.

\begin{tabular}{ccccc}
\hline $\begin{array}{c}\text { Inhibitor in } \\
\mathbf{1 . 0} \mathbf{M ~ H C l}\end{array}$ & $\begin{array}{c}\text { Concentration of } \\
\text { inhibitor } \\
(\mathbf{m o l} / \mathbf{l})\end{array}$ & $\begin{array}{c}\text { Corrosion rate } \\
\left(\mathbf{m g} \cdot \mathbf{c m}^{-\mathbf{2}} \cdot \mathbf{h}^{-\mathbf{1}}\right)\end{array}$ & $\begin{array}{c}\boldsymbol{E}_{\mathbf{p}} \\
\mathbf{( \% )}\end{array}$ & $\boldsymbol{\theta}$ \\
\hline- & - & 0.82 & - & - \\
\hline & $1 \times 10^{-6}$ & 0.22 & 73 & 0.73 \\
$\mathrm{NQPr}$ & $1 \times 10^{-5}$ & 0.15 & 82 & 0.82 \\
& $1 \times 10^{-4}$ & 0.10 & 88 & 0.88 \\
& $1 \times 10^{-3}$ & 0.060 & 93 & 0.93 \\
\hline
\end{tabular}

\section{V.2. Adsorption isotherm}

It is a known fact that adsorption isotherms can be used to explain the interaction between the metal surface and the inhibitor. The degree of surface coverage, $\theta$, was computed for the different concentrations of the 6-nitro-1,4-di(prop-2-yn-1-yl)quinoxaline-2,3(1H,4H)dione from weight loss measurements as follows: $\eta \%=\theta \times 100$, assuming a direct relationship between surface coverage and inhibition efficiency. The surface coverage values were applied to various adsorption isotherm models and the correlation coefficient $\left(R^{2}\right)$ proved useful in determining the best isotherm fit Table 2. Langmuir adsorption isotherm showed the best fit as shown in Figure 3, and formulated as:

$$
\frac{C}{\theta}=\frac{1}{K_{\text {ads }}}+C
$$

Where, $C$ is the concentration of inhibitor, $\theta$ is the surface coverage and $K_{\text {ads }}$ is the adsorption equilibrium constant. 
The values of $K_{\text {ads }}$ were derived from the intercept $\left(1 / K_{\mathrm{ads}}\right)$. The value of $\Delta G_{\mathrm{ads}}$ was calculated using the following equation [20,21].

$$
\Delta G_{\mathrm{ads}}=-R T \ln \left(55.5 K_{\mathrm{ads}}\right)
$$

Where, $T$ is the temperature in Kelvin $(\mathrm{K}), R$ is the universal gas constant and 55.5 is the molar concentration of water of the studied solution.

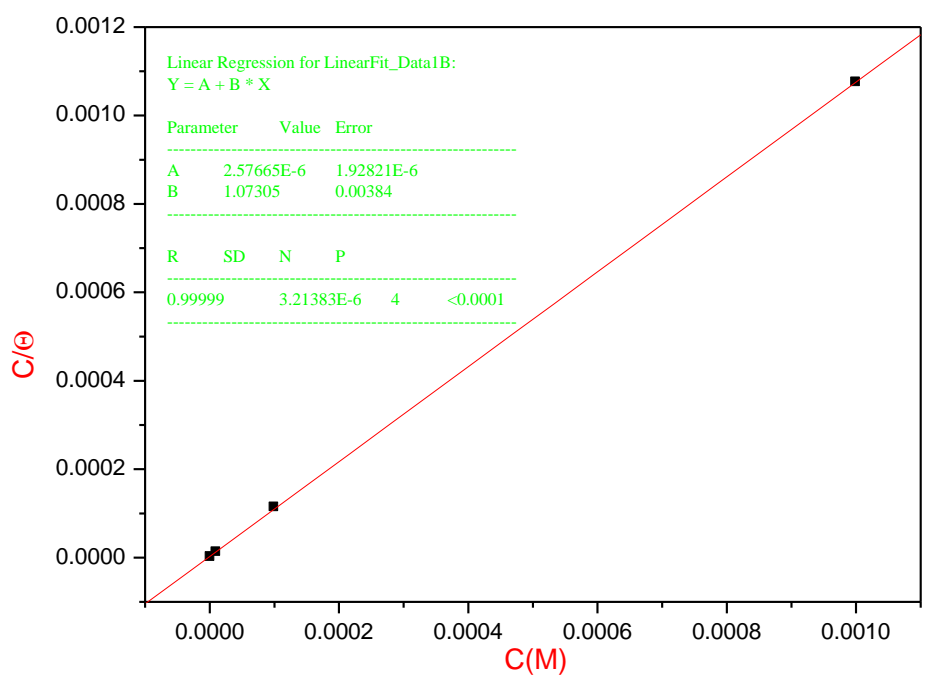

Figure 3. Langmuir adsorption isotherm of mild steel surface in $1.0 \mathrm{M} \mathrm{HCl}$ solution with various concentrations of inhibitor (NQPr).

The molecular interaction parameter can have either a positive or negative value. The positive value shows attractive forces between adsorbed molecules where as a negative one shows repulsive forces between the adsorbed molecules [22, 23].

The values of free energy of adsorption up to $-20 \mathrm{~kJ} \cdot \mathrm{mol}^{-1}$ are consistent with electrostatic interaction between charged molecules and a charged metal (which indicates physical adsorption) while those more negative than $-40 \mathrm{~kJ} \cdot \mathrm{mol}^{-1}$ involves charge sharing or transfer from the inhibitor molecules to the metal surface to form a coordinate type of bond (which indicates chemisorption). The value of free energy of adsorption obtained in this study $\left(-42 \mathrm{~kJ} \cdot \mathrm{mol}^{-1}\right)$ indicated that the chemisorption of the inhibitor (NQPr) on the surface of the mild steel $[24,25]$.

Table 2. The values of $K_{\text {ads }}$ and $\Delta G_{\text {ads }}$ of NQPr inhibitor for mild steel in $1.0 \mathrm{M} \mathrm{HCl}$ solution at $308 \mathrm{~K}$.

\begin{tabular}{cccc}
\hline Inhibitor & $\boldsymbol{K}_{\text {ads }}$ & $-\Delta \boldsymbol{G}_{\text {ads }}(\mathbf{k J} / \mathbf{m o l})$ & $\boldsymbol{R}^{\mathbf{2}}$ \\
\hline NQPr & 388100.83 & 42.28 & 0.99998 \\
\hline
\end{tabular}




\section{V.3. Electrochemical behavior}

The electrochemical parameters such as corrosion current density $\left(I_{\text {corr }}\right)$, corrosion potential $\left(E_{\text {corr }} v s . \mathrm{SCE}\right)$, cathodic and anodic Tafel slopes $\left(\beta_{\mathrm{c}}, \beta_{\mathrm{a}}\right)$ and inhibition efficiency $\left(E_{I} \%\right)$ issued from Figure 3, are given in Table 3. It is clearly noticed that bay increasing NQPr inhibitor concentrations decreases corrosion current densities. The presence of inhibitor resulted in a slight shift of the corrosion potential to-wards the active direction in comparison to the result obtained in the absence of the inhibitor. Both the anodic and cathodic current densities were decreased indicating that the inhibitor suppressed both of the anodic and cathodic reactions. This phenomenon may be due to the existence of the nitrogen atom.

Table 3. Tafel polarization parameters obtained at different concentrations of NQPr in $1.0 \mathrm{M} \mathrm{HCl}$ solution.

\begin{tabular}{ccccccc}
\hline $\begin{array}{c}\text { Inhibitor in } \\
\mathbf{1 . 0} \mathbf{M ~ H C l}\end{array}$ & $\begin{array}{c}\text { Concentration } \\
\text { of inhibitor } \\
(\mathbf{M})\end{array}$ & $\begin{array}{c}-\boldsymbol{E}_{\mathbf{c o r r}} \\
(\mathbf{m V} / \mathbf{S C E})\end{array}$ & $\begin{array}{c}\boldsymbol{I}_{\mathbf{c o r r}} \\
\left(\boldsymbol{\mu} \mathbf{A} / \mathbf{c m}^{2}\right)\end{array}$ & $\begin{array}{c}-\boldsymbol{\beta}_{\mathbf{c}} \\
\left(\boldsymbol{\mu A} \mathbf{A} / \mathbf{c m}^{2}\right)\end{array}$ & $\begin{array}{c}\boldsymbol{\beta}_{\mathbf{a}} \\
\left(\boldsymbol{\mu A} \mathbf{/} \mathbf{c m}^{2}\right)\end{array}$ & $\begin{array}{c}\boldsymbol{E}_{\boldsymbol{I}} \\
(\boldsymbol{\%})\end{array}$ \\
\hline- & - & 465 & 1386 & 164 & 73 & - \\
\hline \multirow{2}{*}{$\mathrm{NQPr}$} & $1.0 \times 10^{-6}$ & 449 & 350 & 157 & 68 & 75 \\
& $1.0 \times 10^{-5}$ & 457 & 294 & 163 & 69 & 79 \\
& $1.0 \times 10^{-4}$ & 454 & 155 & 162 & 71 & 89 \\
\hline
\end{tabular}

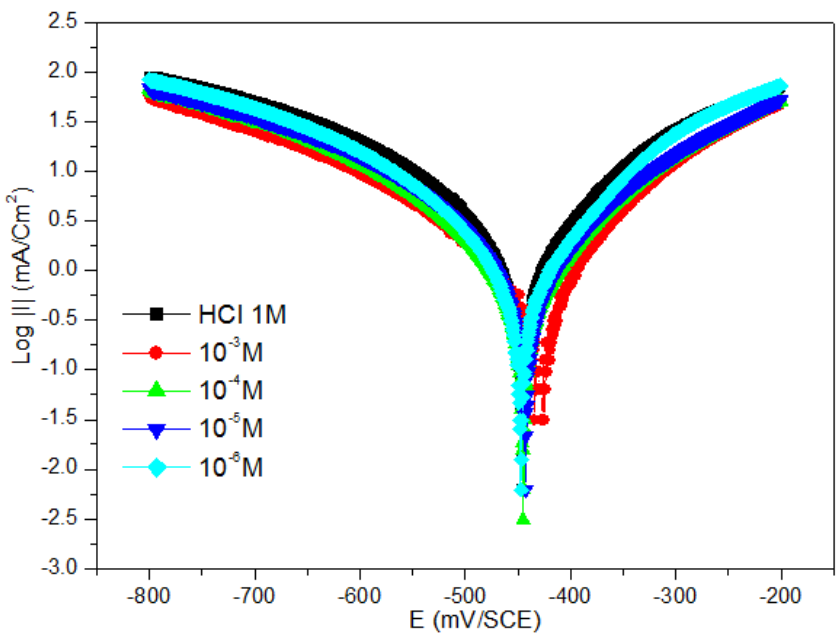

Figure 3. Polarization curves for mild steel in $1.0 \mathrm{M} \mathrm{HCl}$ solution containing different concentrations of NQPr.

In the presence of inhibitor NQPr in $1.0 \mathrm{M} \mathrm{HCl}$, both anodic-cathodic Tafel slopes almost remain unchanged (Figure 3), indicating that the inhibitor acted by merely blocking 
the reaction sites of the metal surface without changing the anodic and cathodic reaction mechanisms. The overall results suggest that the investigated inhibitor NQPr acts as a mixed-type. It is observed that the inhibition efficiency increases with increasing concentration of the inhibitor. The highest inhibition efficiency reaches a maximum value of $91 \%$ at optimum concentration $\left(1.0 \times 10^{-3} \mathrm{M}\right)$ of NQPr.

\section{V.4. Electrochemical impedance measurements}

Impedance spectra for mild steel in $1.0 \mathrm{M} \mathrm{HCl}$ solution in the absence and presence of various concentrations of (NQPr) were similar in shape and are shown in Figure 4. The semicircle in all cases corresponds to a capacitive loop. The semicircle depends on the concentration of the additive inhibitor NQPr. The diameter of the capacitive loop increases with increasing concentration of NQPr. The capacitive loop indicated the formation of surface film.

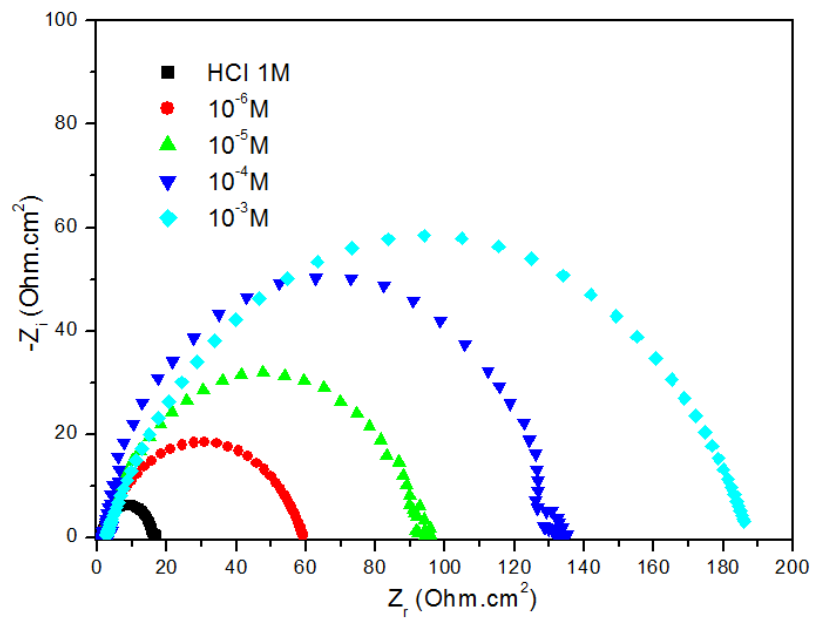

Figure 4. Nyquist diagrams for mild steel in $1.0 \mathrm{M} \mathrm{HCl}$ solution containing different concentrations of NQPr.

The Nyquist plots represented in Figure 4 were analyzed by best fitting to the equivalent circuit model shown in Figure 5 and the values of the symbols of this circuit can be defined according to usual convention, as follows; $R_{\mathrm{S}}$ represents the solution resistance, $R_{\mathrm{ct}}$ is the charge transfer resistance, and CPE is the constant phase elements.

Figure 5 depicts the proposed equivalent circuit, which consists of a solution resistance $R \mathrm{~s}$ in series to the constant phase element CPE and the charge transfer resistance $\mathrm{R}_{\mathrm{ct}}$ while CPE is parallel to $R_{\mathrm{ct}}$. Same equivalent circuit was proposed in the literature for acidic corrosion of mild steel in presence of inhibitor organic [26]. The use of CPE-type impedance has been extensively stated by previous reports [27]. 


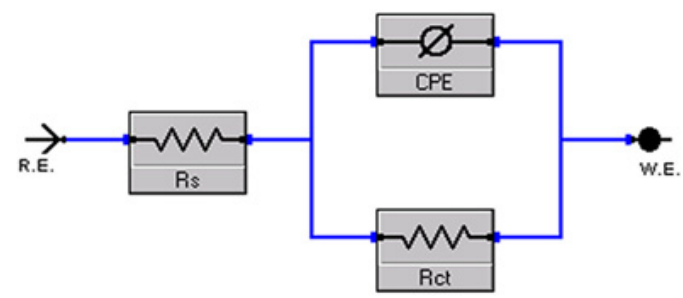

Figure 5. Electrical equivalent circuit used for modelling metal/solution interface in $1.0 \mathrm{M}$ $\mathrm{HCl}$ solution in the absence and presence of NQPr inhibitor.

Table 4. Impedance parameters for corrosion of mild steel in $1 \mathrm{M} \mathrm{HCl}$ in the absence and presence of different concentrations of NQPr.

\begin{tabular}{ccccc}
\hline $\begin{array}{c}\text { Inhubitor in } \\
\mathbf{1 . 0} \mathbf{M ~ H C l}\end{array}$ & $\begin{array}{c}\text { Concentration of } \\
\text { inhibitor }(\mathbf{M})\end{array}$ & $\begin{array}{c}\boldsymbol{R}_{\mathbf{c t}} \\
\left(\boldsymbol{\Omega} \cdot \mathbf{c m}^{2}\right)\end{array}$ & $\begin{array}{c}\boldsymbol{C}_{\mathbf{d l}} \\
\left(\boldsymbol{\mu} \mathbf{F} / \mathbf{c m}^{2}\right)\end{array}$ & $\begin{array}{c}\boldsymbol{E}_{\mathbf{E I S}} \\
(\boldsymbol{\%})\end{array}$ \\
\hline- & - & 15 & 200 & - \\
\hline \multirow{3}{*}{$\mathrm{NQPr}$} & $1.0 \times 10^{-6}$ & 60 & 127 & 76 \\
& $1.0 \times 10^{-5}$ & 93 & 91 & 84 \\
& $1.0 \times 10^{-4}$ & 130 & 66 & 89 \\
& $1.0 \times 10^{-3}$ & 185 & 41 & 92 \\
\hline
\end{tabular}

\section{V.5. Quantum chemical calculations}

In the last few years, the FMOs (HOMO and LUMO) are widely used for describing chemical reactivity. The HOMO containing electrons, represents the ability $\left(E_{\mathrm{HOMO}}\right)$ to donate an electron, whereas, LUMO haven't not electrons, as an electron acceptor represents the ability ( $\left.E_{\mathrm{LUMO}}\right)$ to obtain an electron. The energy gap between HOMO and LUMO determines the kinetic stability, chemical reactivity, optical polarizability and chemical hardness-softness of a compound [28].

Table 5. Quantum chemical descriptors of the studied inhibitor NQPr at B3LYP/6-31G(d,p) in the gaseous $(\mathrm{G})$ phase.

\begin{tabular}{cc}
\hline Parameter & Gaseous Phase \\
\hline Total Energy $T E(\mathrm{eV})$ & -27305.2 \\
$E_{\mathrm{HOMO}}(\mathrm{eV})$ & -7.2498 \\
$E_{\mathrm{LUMO}}(\mathrm{eV})$ & -4.9073 \\
Gap $\Delta E(\mathrm{eV})$ & 2.3425 \\
Dipole moment $\mu($ Debye $)$ & 2.9627 \\
Ionization potential $I(\mathrm{eV})$ & 7.2498 \\
Electron affinity $A$ & 4.9073
\end{tabular}




\section{Parameter}

Electronegativity $\chi$

Hardness $\eta$

Electrophilicity index $\omega$

Softness $\sigma$

\section{Gaseous Phase}

6.0786

1.1713

15.7733

0.8538

0.3933

Fraction of electron transferred $\Delta N$

In this paper, the HOMO and LUMO orbital energies were calculated by using B3LYP method with 6-31G(d,p). All other calculations were performed using the results with some assumptions. The higher values of $E_{\mathrm{HOMO}}$ indicate an increase for the electron donorability of the inhibitorand this means a better inhibitory activity with increasing adsorption of the inhibitor on the mild steel surface, where as higher values of $E_{\mathrm{LUMO}}$ indicate the ability of the inhibitor to accept electrons. The adsorption ability of the inhibitor to the metal surface increases with increasing of $E_{\text {HOMO }}$ and decreasing of $E_{\mathrm{LUMO}}$. High ionization energy ( $I=7.2498 \mathrm{eV}$ in gas) indicates high stability $[29,30]$, the number of electrons transferred $(\Delta N)$ was also calculated and tabulated in Table 5 . The number of electrons transferred $(\Delta N)$ was also calculated and tabulated in Table 6 . The $\Delta N$ (gas) $<3.6$ indicates the tendency of the inhibitor molecule to donate electrons to the metal surface [31-33].

The final optimized geometries of NQPr in the gaseous phase $(\mathrm{G})$, selected valence bond angle and dihedral angles and bond lengths are given in Figure 6.

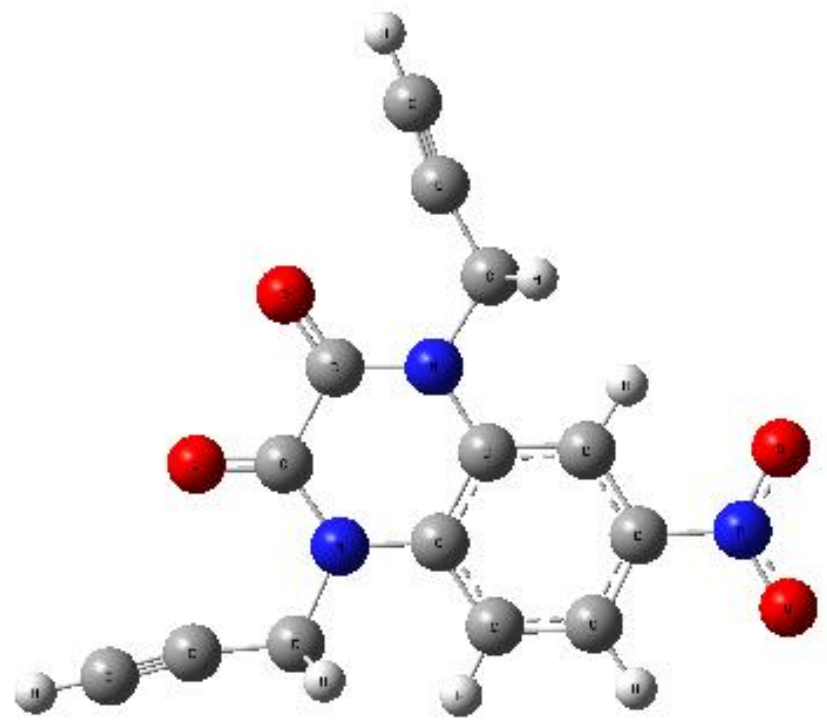

Figure 6. Optimized molecular structure of NQPr inhibitor calculated at B3LYP/6-31G(d, p) level. 
The analysis of the theoretical results, indicate that the quinoxaline ring in the inhibitor molecule NQPr is almost planar as shown in Figure 7.

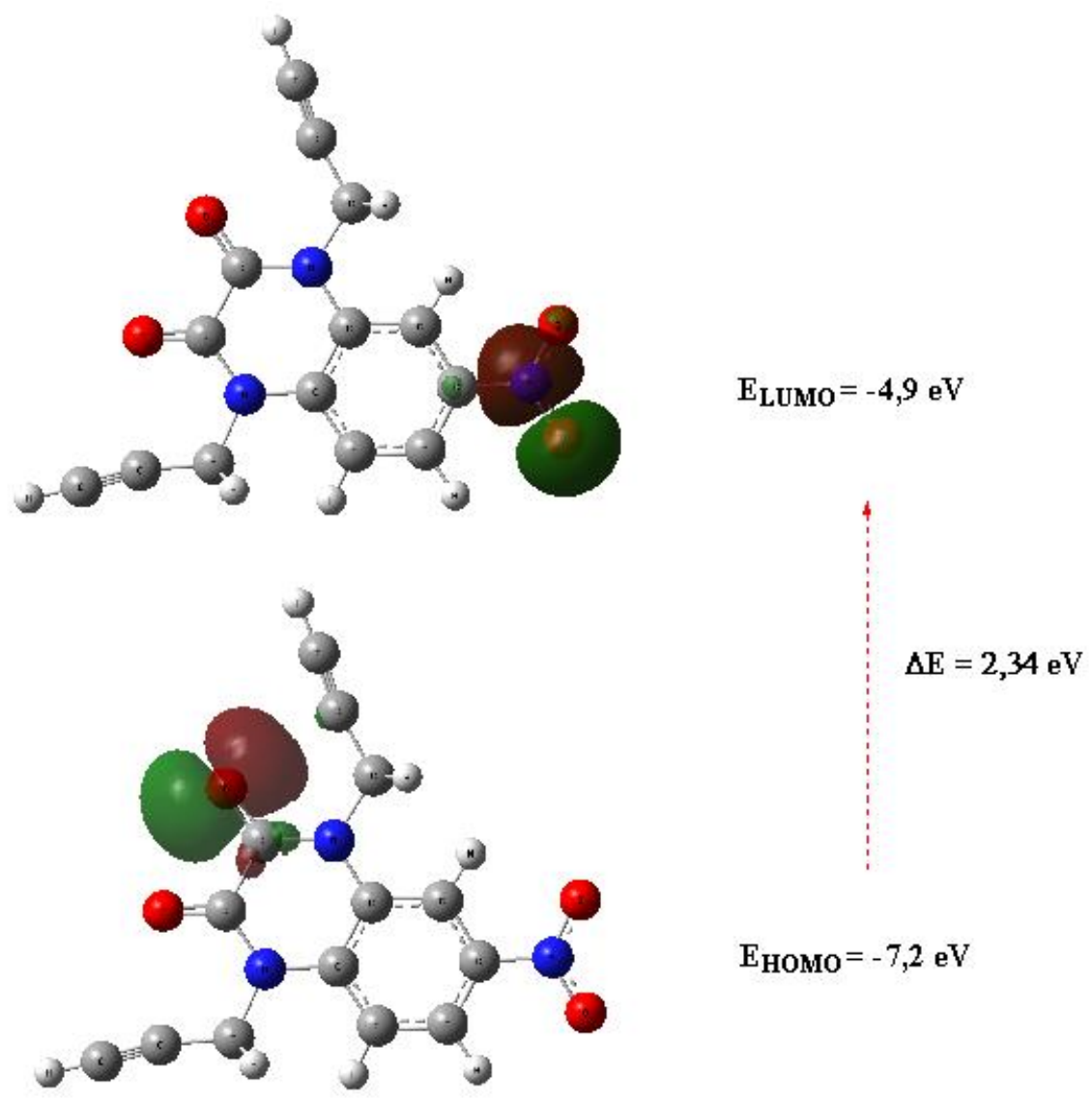

Figure 7. The HOMO and the LUMO electrons density distributions of the studied NQPr inhibitor computed at B3LYP/6-31G(d,p) level in the gaseous phase.

The inhibition efficiency afforded by the quinoxaline derivative NQPr may be attributed to the presence of lone pairs of electrons on $\mathrm{O}$ and $\mathrm{N}$ atoms as well as the pi electrons of the aromatic quinoxaline ring.

\section{Conclusion}

In this study, inhibitive performance of 6-nitro-1,4-di(prop-2-yn-1-yl)quinoxaline2,3(1H,4H)-dione (NQPr) for mild steel in $1.0 \mathrm{M} \mathrm{HCl}$ solution has been studied and arrived at these results:

1. NQPr showed an excellent inhibitive action against mild steel in $1.0 \mathrm{M} \mathrm{HCl}$ solution, such that increase in the inhibitor concentration causes a remarkable improvement on their efficiencies.

2. The adsorption of NQPr on the mild steel surface obeys Langmuir adsorption isotherm model. Chemical adsorption mechanism is proposed from the activation energy and other thermodynamic parameters. 
3. There was good agreement between the data obtained from weight loss and electrochemical methods.

4. Potentiodynamic polarization measurements indicate that the NQPr acts as a mixed type inhibitor.

5. Impedance considerations show that increasing the inhibitor increases the solution resistance considerably in all studied concentrations.

6. The calculated quantum chemical parameters such as HOMO-LUMO gap, $E_{\text {Hомо, }}$ $E_{\text {LUMo, dipole moment }}(\mu)$ and total energy $(T E)$ were found to give reasonably good correlation with the efficiency of the corrosion inhibition experimental results.

\section{References}

1. A.Dell, D.H. William, H.R. Morris, G.A. Smith, J. Freeney and G.C.K. Roberts, J. Am. Chem. Soc., 1975, 97, 2497-2502.

2. R.H. Bahekar, M.R. Jain, A.A. Gupta, A. Goel, P.A. Jadav, D.N. Patel, V.M. Prajapati and P.R. Patel, Arch. Pharm. (Weinheim, Ger.), 2007, 340, 359-366. doi: 10.1002/ardp.200700024

3. A. Carta, G. Paglietti, M.E.R. Nikookar, P. Sanna, L. Sechi and S. Zanetti., Eur. J. Med. Chem., 2002, 37, 355-366.

4. O.I. El-Sabbagh, M.E. El-Sadek, S.M. Lashine, S.H. Yassin and S.M. El-Nabtity, Med. Chem. Res., 2009, 18, 782-797.

5. D. Gupta, N.N. Ghosh and R. Chandra, Bioorg. Med. Chem. Lett., 2005, 15, 10191022.

6. K. Sasse, R. Weger, G. Untersten Hoefer and F. Grewe, Angew. Chem., 1960, 72, 973-981.

7. A. El Janati, Y. Kandri Rodi, H. Elmsellem, F. Ouazzani Chahdi, A. Aouniti, B. El Mahi, Y. Ouzidan, N.K. Sebbar and E.M. Essassi, J. Mater. Environ. Sci., 2016, 7, 4311-4323.

8. M.J. Frisch, G.W. Trucks, H.B. Schlegel et al., Gaussian 09, Revision A.1, Gaussian, Inc., Wallingford, Conn., USA, 2009.

9. H. Elmsellem, M.H. Youssouf and A. Aouniti, Russ. J. Appl. Chem., 2014, 8, 744-753.

10. K. Efil and Y.Bekdemir, Can. Chem. Trans., 2015, 3, 85. doi: 10.13179/canchemtrans.2015.03.01.0165

11. L. Pauling, The nature of the chemical bond, 3rd ed., Cornell University Press, Ithaca, 1960.

12. K.D. Sen and C.K. Jorgenson, Structure and Bonding, Electronegativity, Springer: Berlin, 1987, 66.

13. K.D. Sen and D.M.P. Mingos, Structure and Bonding, Springer-Verlag, Berlin, 1993, 80, 11-25. 
14. R.G. Parr and W.Yang, Density-Functional Theory of Atoms and Molecules, Oxford University Press, New York, 1989.

15. P. Geerlings, F. De Proft and W. Langenaeker, Chem. Rev., 2003, 103, 1793-1874.

16. H. Chermette, J. Comput. Chem., 1999, 20, 129.

17. R.G. Pearson, Inorg. Chem., 1988, 27, 734-740.

18. V.S. Sastri and J.R. Perumareddi, Corrosion, 1997, 3, 671.

19. P. Udhayakala, T.V. Rajendiran and S. Gunasekaran, J. Chem., Biol. Phys. Sci., 2012, 2, 1151-1165.

20. S. Attabi, M. Mokhtari, Y. Taibi, I. Abdel-Rahman and B. Hafez, J. Bio. Tribo. Corros., 2019, 5, 2. doi: 10.1007/s40735-018-0193-5

21. H. Elmsellem, Y.El Ouadi, M. Mokhtari, H. Steli, A. Aouniti, A.M. Almehdi, I. AbdelRahman and H.S. Kusuma, J. Chem. Technol. Metall., 2019, 54, 742-749.

22. D.A. Lopez, S.N. Simison and S.R. de Sanchez, Electrochim. Acta, 2003, 48, no. 7, $845-854$.

23. E.A. Skrypnikova and S.A. Kaluzhina, Int. J. Corros. Scale Inhib., 2015, 4, no. 2, 139145. doi: $10.17675 / 2305-6894-2015-4-1-139-145$

24. H.A. El-Shayeb, A. El-Warraky and E.M. Sherif, Anti-Corros. Methods Mater., 2004, 51, 52. doi: $10.1108 / 00035590410512735$

25. D.A. Lopez, S.N. Simison and S.R. de Sanchez, Electrochim. Acta, 2003, 48, no. 7, $845-854$.

26. Yu.I. Kuznetsov and L.P. Kazansky, Russ. Chem. Rev., 2008, 77, 230.

27. K.R. Ansari, S. Ramkumar, D.S. Chauhan, Md. Salman, D. Nalini, V. Srivastava and M.A. Quraishi, Int. J. Corros. Scale Inhib., 2018, 7, no. 3, 443-459. doi: 10.17675/2305-6894-2018-7-3-13

28. M. Govindarajan and M. Karabacak, Spectrochim. Acta, Part A, 2012, 85, 251-260. doi: $\underline{10.1016 / j . s a a .2011 .10 .002}$

29. M. Sikine, Y. Kandri Rodi, O. Krim, H. Steli, Y. Ouzidan, A. Kandri Rodi, F. Ouazzani Chahdi, N.K. Sebbar and E.M. Essassi, J. Mater. Environ. Sci., 2016, 7, no. 4, 1386-1395.

30. H. Elmsellem, H. Nacer, F. Halaimia, A. Aouniti, I. Lakehal, A. Chetouani and B. Hammouti, Int. J. Electrochem. Sci., 2014, 9, 5328-5351.

31. I. Lukovits, E. Kalman and F. Zucchi, Corrosion, 2001, 57, 3-7.

32. Y. Filali Baba, H. Elmsellem, Y. Kandri Rodi, H. Steli, C. AD, Y. Ouzidan, F. Ouazzani Chahdi, N.K. Sebbar, E.M. Essassi and B. Hammouti, Pharma Chem., 2016, 8, no. 4, 159-169.

33. C. Verma, M.A. Quraishi and A. Singh, J. Mol. Liq., 2015, 212, 804-812. 